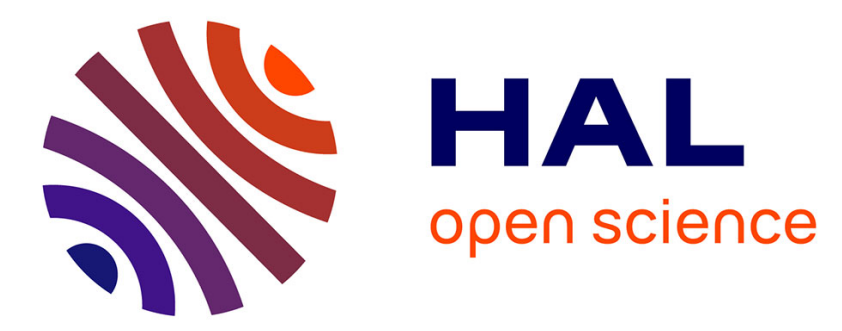

\title{
Topotactically constructed nickel-iron (oxy)hydroxide with abundant in-situ produced high-valent iron species for efficient water oxidation
}

Zhichong Kuang, Song Liu, Xuning Li, Meng Wang, Xinyi Ren, Jie Ding, Rile Ge, Wenhui Zhou, Alexandre Rykov, Moulay Tahar Sougrati, et al.

\section{To cite this version:}

Zhichong Kuang, Song Liu, Xuning Li, Meng Wang, Xinyi Ren, et al.. Topotactically constructed nickel-iron (oxy)hydroxide with abundant in-situ produced high-valent iron species for efficient water oxidation. Journal of Energy Chemistry, 2021, 57, pp.212-218. 10.1016/j.jechem.2020.09.014 . hal02988388

\section{HAL Id: hal-02988388 \\ https://hal.science/hal-02988388}

Submitted on 13 Nov 2020

HAL is a multi-disciplinary open access archive for the deposit and dissemination of scientific research documents, whether they are published or not. The documents may come from teaching and research institutions in France or abroad, or from public or private research centers.
L'archive ouverte pluridisciplinaire HAL, est destinée au dépôt et à la diffusion de documents scientifiques de niveau recherche, publiés ou non, émanant des établissements d'enseignement et de recherche français ou étrangers, des laboratoires publics ou privés. 


\section{Journal Pre-proofs}

Topotactically constructed nickel-iron (oxy)hydroxide with abundant in-situ produced high-valent iron species for efficient water oxidation

Zhichong Kuang, Song Liu, Xuning Li, Meng Wang, Xinyi Ren, Jie Ding, Rile Ge, Wenhui Zhou, Alexandre I. Rykov, Moulay T. Sougrati, PierreEmmanuel Lippens, Yanqiang Huang, Junhu Wang

PII: S2095-4956(20)30649-5

DOI: https://doi.org/10.1016/j.jechem.2020.09.014

Reference: JECHEM 1596

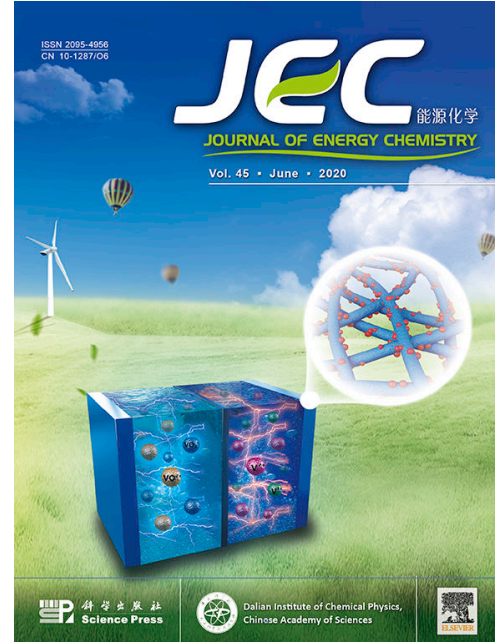

To appear in: Journal of Energy Chemistry

Received Date:

16 August 2020

Revised Date:

10 September 2020

Accepted Date:

15 September 2020

Please cite this article as: Z. Kuang, S. Liu, X. Li, M. Wang, X. Ren, J. Ding, R. Ge, W. Zhou, A.I. Rykov, M.T. Sougrati, P-E. Lippens, Y. Huang, J. Wang, Topotactically constructed nickel-iron (oxy)hydroxide with abundant in-situ produced high-valent iron species for efficient water oxidation, Journal of Energy Chemistry (2020), doi: https://doi.org/10.1016/j.jechem.2020.09.014

This is a PDF file of an article that has undergone enhancements after acceptance, such as the addition of a cover page and metadata, and formatting for readability, but it is not yet the definitive version of record. This version will undergo additional copyediting, typesetting and review before it is published in its final form, but we are providing this version to give early visibility of the article. Please note that, during the production process, errors may be discovered which could affect the content, and all legal disclaimers that apply to the journal pertain. 


\title{
Topotactically constructed nickel-iron (oxy)hydroxide with
}

\section{abundant in-situ produced high-valent iron species for efficient water oxidation}

Zhichong Kuang, ${ }^{\mathrm{a}, \mathrm{b}, \mathrm{c}}$, Song Liu ${ }^{\mathrm{b}, \mathrm{d}}$, Xuning $\mathrm{Li}^{\mathrm{a}, \mathrm{d}, \mathrm{g}}$, Meng Wang ${ }^{\mathrm{e}}$, Xinyi Ren ${ }^{\mathrm{b}, \mathrm{d}}$, Jie Ding ${ }^{\mathrm{d}}$, Rile Ge ${ }^{\mathrm{a}, \mathrm{c}}$, Wenhui Zhou ${ }^{\mathrm{a}, \mathrm{c}}$, Alexandre I. Rykov ${ }^{\mathrm{a}, \mathrm{c}}$, Moulay T. Sougrati ${ }^{\mathrm{f}}$, PierreEmmanuel Lippens ${ }^{\mathrm{f}}$, Yanqiang Huang ${ }^{\mathrm{d}}$, Junhu Wang ${ }^{\mathrm{a}, \mathrm{c}, *}$

${ }^{a}$ Center for Advanced Mössbauer Spectroscopy, Dalian Institute of Chemical Physics, Chinese Academy of Sciences, Dalian 116023, Liaoning, China

${ }^{b}$ University of Chinese Academy of Sciences, Beijing 100049, China

${ }^{c}$ State Key Laboratory of Catalysis, Dalian Institute of Chemical Physics, Chinese Academy of Sciences, Dalian 116023, Liaoning, China

${ }^{d}$ CAS Key Laboratory of Science and Technology on Applied Catalysis, Dalian Institute of Chemical Physics, Chinese Academy of Sciences, Dalian 116023, Liaoning, China ${ }^{e}$ Department of Chemistry and Biotechnology, School of Engineering, Nagoya University, Nagoya 464-8601, Japan

${ }^{f}$ Institut Charles Gerhard, UMR 5253, CNRS, Université de Montpellier, Place Eugène Bataillon, 34095 Montpellier Cedex 5, France

${ }^{g}$ Nanyang Technological University, Singapore 637459, Singapore

${ }^{*}$ Corresponding author. E-mail address: wangjh@dicp.ac.cn (J. Wang).

\begin{abstract}
The low efficiency of oxygen evolution reaction (OER) is regarded as one of the major roadblocks for metal-air batteries and water electrolysis. Herein, a high-performance OER catalyst of $\mathrm{NiFe}_{0.2}$ (oxy)hydroxide $\left(\mathrm{NiFe}_{0.2}-\mathrm{O}_{x} \mathrm{H}_{y}\right)$ was developed through topotactic transformation of a Prussian blue analogue in an alkaline solution, which exhibits a low overpotential of only $263 \mathrm{mV}$ to reach a current density of $10 \mathrm{~mA} \mathrm{~cm}^{-2}$

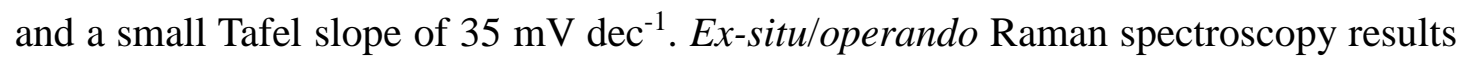
indicated that the phase structure of $\mathrm{NiFe}_{0.2}-\mathrm{O}_{x} \mathrm{H}_{y}$ was irreversibly transformed from the type of $\alpha-\mathrm{Ni}(\mathrm{OH})_{2}$ to $\gamma-\mathrm{NiOOH}$ with applying an anodic potential, while $e x$ -
\end{abstract}


situ/operando ${ }^{57} \mathrm{Fe}$ Mössbauer spectroscopic studies evidenced the in-situ production of abundant high-valent iron species under OER conditions, which effectively promoted the OER catalysis. Our work elucidates that the amount of high-valent iron species in-situ produced in the NiFe (oxy)hydroxide has a positive correlation with its water oxidation reaction performance, which further deepens the understanding of the mechanism of NiFe-based electrocatalysts.

Keywords: Oxygen evolution reaction; Topotactic construction; Structural transformation; Operando Mössbauer spectroscopy; High-valent iron ion

\section{Introduction}

Oxygen evolution reaction (OER), as a core reaction in water electrolysis and for the storage of renewable electricity, has received lots of research attentions over the past few years [1-4]. The development of low-cost and high-efficiency OER catalysts with low overpotential and high stability is of great significance for the renewable energy technologies [5-8].

Among the various studied low-cost OER catalysts, NiFe-based (oxy)hydroxide materials show excellent catalytic activities [9-15]. Previous studies have evidenced that the water oxidation is usually proceeded via the nucleophilic attack of water molecule or hydroxide ions on the high-valent $\mathrm{Fe}$ or $\mathrm{Ni}$ center (such as $\mathrm{Fe}^{4+}$ or $\mathrm{Ni}^{4+}$ ) over NiFe (oxy)hydroxides during OER [16-19]. For instance, Stahl et al. discovered that the $\mathrm{NiOOH}$ lattice could promote the formation of $\mathrm{Fe}^{4+}$ and experimentally evidenced the existence of $\mathrm{Fe}^{4+}$ using ex-situloperando ${ }^{57} \mathrm{Fe}$ Mössbauer spectroscopy under OER conditions [17]. Density functional theory (DFT) calculations performed by Goldsmith and co-workers confirmed the critical role of $\mathrm{NiOOH}$ lattice for boosting the oxidation of $\mathrm{Fe}^{3+}$ to $\mathrm{Fe}^{4+}$ [20]. However, up to know, the real active center and the role of $\mathrm{Fe}^{4+}$ in $\mathrm{NiFe}$-based (oxy)hydroxide for OER are still under debate. 
In this work, a series of $\mathrm{NiFe}_{m}$ (oxy)hydroxide $\left(\mathrm{NiFe}_{m}-\mathrm{O}_{x} \mathrm{H}_{y}, m\right.$ refers to the atomic ratio of $\mathrm{Fe} / \mathrm{Ni}$ ) catalysts were synthesized by the topotactic transformation of $\mathrm{NiFe}_{m}-\mathrm{Fe}$ Prussian blue analogues (PBAs) in an alkaline solution. An optimized OER catalytic performance with a low overpotential of $263 \mathrm{mV}$ and a small Tafel slope of $35 \mathrm{mV} \mathrm{\textrm {dec } ^ { - }}$ ${ }^{1}$ at the current density of $10 \mathrm{~mA} \mathrm{~cm}^{-2}$ in $1.0 \mathrm{M} \mathrm{KOH}$ aqueous solution was achieved over the optimized $\mathrm{NiFe}_{0.2}-\mathrm{O}_{x} \mathrm{H}_{y}$, which is superior to the state-of-the-art $\mathrm{RuO}_{2}$ catalyst. Ex-situ/operando Raman spectroscopy results showed that the phase structure of $\mathrm{NiFe}_{0.2}-\mathrm{O}_{x} \mathrm{H}_{y}$ was irreversibly converted from the type of $\alpha-\mathrm{Ni}(\mathrm{OH})_{2}$ to $\gamma-\mathrm{NiOOH}$ under an applied anodic potential. Furthermore, ex-situ/operando Mössbauer spectroscopy measurements evidenced the in-situ production of abundant high-valent iron species near the OER onset potential. A positive correlation between the amount of the highvalent iron ions and the OER activities at various applied potentials was observed in the first time, which is vitally useful to insight into the catalyzing mechanism of the water oxidation reaction over $\mathrm{NiFe}$-based (oxy)hydroxide electrocatalysts.

\section{Experimental}

\subsection{Materials}

Ferrous chloride and nickel nitrate were purchased from Tianjin Daomao Chemical Reagent Co., Ltd., China. Potassium hexacyanocobaltate(III) (98\%) was purchased from Beijing J\&K Co., Ltd., China. Potassium chloride (99\%) and potassium hydroxide (95\%) were purchased from Sigma-Aldrich. Nafion solution (5 wt\%) was obtained from Alfa Aesar. All chemical reagents were used without further purification.

\subsection{Sample preparation}

\subsubsection{Preparation of $\mathrm{NiFe}_{m}-\mathrm{Fe} \mathrm{PBAs}, \mathrm{m}=0.11,0.20,0.25,0.29$}

$\mathrm{NiFe}_{m}\left[\mathrm{Fe}(\mathrm{CN})_{6}\right]_{m+(2 / 3)}\left(\mathrm{NiFe}_{m}-\mathrm{Fe}\right.$ PBAs, $\left.m=0.11,0.20,0.25,0.29\right)$ was prepared by a coprecipitation method [21]. It is described here that the synthesis process of 
$\mathrm{NiFe}_{0.20}-\mathrm{Fe} \mathrm{PBA}$, the other samples are prepared by the same method, except for changing the different $\mathrm{Fe} / \mathrm{Ni}$ molar ratios. Briefly, $987.8 \mathrm{mg}$ of $\mathrm{K}_{3}\left[\mathrm{Fe}(\mathrm{CN})_{6}\right]$ was dissolved in $300 \mathrm{~mL}$ ultrapure water $(18.2 \mathrm{M} \Omega$ ) in a $500 \mathrm{~mL}$ beaker (solution A with 10 M concentration). Meanwhile, $822.8 \mathrm{mg}$ of $\mathrm{NiCl}_{2} \cdot 6 \mathrm{H}_{2} \mathrm{O}$ and $187.1 \mathrm{mg}$ of $\mathrm{FeCl}_{3}$ were dissolved in $600 \mathrm{~mL}$ ultrapure water in a $1 \mathrm{~L}$ beaker (solution B with $11.5 \mathrm{M}$ $\mathrm{NiCl}_{2} \cdot 6 \mathrm{H}_{2} \mathrm{O}$ and $2.3 \mathrm{M} \mathrm{FeCl}_{3} \cdot 6 \mathrm{H}_{2} \mathrm{O}$ ). Then solution A was dropwise added into solution B, followed by stirring for $30 \mathrm{~min}$ and aging for $20 \mathrm{~h}$. Finally, the produced precipitates were centrifuged and washed at least three times using ultrapure water and then dried at $333 \mathrm{~K}$ in an electric oven for $12 \mathrm{~h}$.

\subsubsection{Preparation of $\mathrm{NiFe}_{m}-\mathrm{O}_{x} \mathrm{H}_{y}$ electrocatalysts, $m=0.11,0.20,0.25,0.29$}

Like the reason in the previous section, the preparation of $\mathrm{NiFe}_{m}-\mathrm{O}_{x} \mathrm{H}_{y}$ electrocatalysts $(m=0.11,0.20,0.25,0.29)$ was explained by that of $\mathrm{NiFe}_{0.2}-\mathrm{O}_{x} \mathrm{H}_{y} .200$ mg of $\mathrm{NiFe}_{0.2}$-Fe PBA was suspended in $100 \mathrm{~mL}$ ultrapure water, followed by adding $200 \mathrm{~mL} 2 \mathrm{M} \mathrm{KOH}$ aqueous solution under vigorous stirring. $15 \mathrm{~min}$ later, the product was centrifuged and washed with ultrapure water several times and dried in vacuum oven for $20 \mathrm{~h}$.

\subsection{Conventional characterization techniques}

The structure of the as-prepared catalysts was characterized by X-ray diffraction (XRD) on a PANalytical X'Pert-Pro X-ray diffractometer with Ni-filtered $\mathrm{Cu} K_{\alpha}(\lambda=$ $0.1154 \mathrm{~nm}$ ) radiation source. The X-ray photoelectron spectroscopy (XPS) measurements were performed on an ESCALAB 250 X-ray photoelectron spectroscope with monochromatic $\mathrm{Al} \mathrm{K \alpha}$ radiation. All binding energies were calibrated by a standard sample of carbon $(\mathrm{C} 1 s=284.8 \mathrm{eV})$. High-resolution transmission electron microscopy (HRTEM), selected area electron diffraction (SAED), and energy dispersive X-ray spectroscopy (EDX) measurements were conducted on a JEOL 
JEMARM200F. The Fe/Ni content were quantified by inductively coupled plasma optical emission spectroscopy (ICP-OES; ICPS-8100, Shimadzu).

\subsection{Electrochemical measurements}

All OER activities of $\mathrm{NiFe}_{m}-\mathrm{O}_{x} \mathrm{H}_{y}$ were performed on a typical three-electrode cell, which used a rotating disk electrode (RDE) (Pine Instrument Company, at a rotation speed of $1600 \mathrm{rpm}$ ) with a CHI 660E electrochemical workstation at ambient temperature. The graphite rod (diameter, $6 \mathrm{~mm}$ ) and saturated calomel electrode (saturated potassium chloride solution) was used as the counter and reference electrodes, respectively. Glassy carbon electrode $\left(5 \mathrm{~mm}\right.$ diameter, $\left.0.196 \mathrm{~cm}^{2}\right)$ coated with catalyst was used as the working electrode. To prepare the working electrode, carbon nanotubes treated by acid were mixed with the as-prepared catalyst to increase the conductivity ( 8 $\mathrm{wt} \%$ ). About $4 \mathrm{mg}$ of the catalyst was added into $1 \mathrm{~mL}$ of Nafion solution (5 wt $\%$ ), and sonicated for at least $6 \mathrm{~h}$ to obtain the catalyst ink. Then the catalyst ink was drop-casted onto the glassy carbon electrode with a mass loading of $0.20 \mathrm{mg} \mathrm{cm}^{-2}$, and dried naturally in air. 1.0 $\mathrm{M} \mathrm{KOH}$ aqueous solution was used as the electrolyte and all electrochemical experiments were carried out at room temperature.

The Ni foam supported with the $\mathrm{NiFe}_{0.2}-\mathrm{O}_{x} \mathrm{H}_{y}$ as working electrode to prevent the catalyst from falling off electrode at large current density in stability testing. In stability test, graphite rod (diameter, $6 \mathrm{~mm}$ ) and saturated calomel electrode (saturated potassium chloride solution) also was used as the counter and reference electrodes, respectively, and the catalyst ink was drop-dried onto Ni foam (thickness, $0.34 \mathrm{~mm}$ ) as working electrode.

All potentials were converted to the reversible hydrogen electrode (RHE) scale according to the following Nernst equation Eq. (1). Before electrochemical test, the asprepared electrode was activated via cyclic voltammetry at a scan rate of $10 \mathrm{mV} \mathrm{s}^{-1}$. 


$$
E_{(\mathrm{vs} . \mathrm{RHE})}=E_{(\mathrm{vs} . \mathrm{SCE})}+0.0591 \times p H+0.241
$$

\subsection{Ex-situ/operando Raman and ${ }^{57} \mathrm{Fe}$ Mössbauer characterization techniques}

The ex-situ/operando Raman spectra were collected on a Renishaw InVia microprobe Raman spectrometer with a $532 \mathrm{~nm}$ excitation laser. A self-developed insitu/operando Raman characterization cell was used for the operando measurements as shown in Fig. S1. During the operando measurements, $\mathrm{Ag} / \mathrm{AgCl}$ electrode and platinum wire were used as reference and counter electrodes, respectively. The potentials were converted to the reversible hydrogen electrode (RHE) scale according to Eq. (2). The prepared $\mathrm{NiFe}_{0.2}-\mathrm{O}_{x} \mathrm{H}_{y}$ catalyst inks were separately drop-dried onto a $1.0 \mathrm{~cm} \times 2.0 \mathrm{~cm}$ glassy carbon sheet as work electrode.

$$
E_{(\mathrm{vs} . \mathrm{RHE})}=E_{(\mathrm{vs} . \mathrm{Ag} / \mathrm{AgCl})}+0.0591 \times p H+0.197 \mathrm{~V}
$$

The ex-situ/operando ${ }^{57} \mathrm{Fe}$ Mössbauer spectra were recorded using a proportional counter and a Topologic 500A spectrometer with ${ }^{57} \mathrm{Co}(\mathrm{Rh})$ as a $\gamma$-ray radioactive source. The spectra were fitted by using the MossWinn 4.0 program, and ${ }^{57} \mathrm{Fe}$ isomer shift values were given relative to $\alpha$-iron as a standard. The operando Mössbauer spectroscopy measurements were performed on a set of self-developed operando electrochemical ${ }^{57} \mathrm{Fe}$ Mössbauer instrument as schematically shown in Scheme 1 and Fig. S2, which can be applied for dynamically observe the evolution of chemical state of the iron in the catalyst during electrochemical reactions. During the operando measurements, the prepared $\mathrm{NiFe}_{0.2}-\mathrm{O}_{x} \mathrm{H}_{y}$ catalyst ink was evenly coated on the carbon paper as work electrode, $\mathrm{Ag} / \mathrm{AgCl}$ electrode and platinum wire were used as the reference and counter electrodes, respectively. 


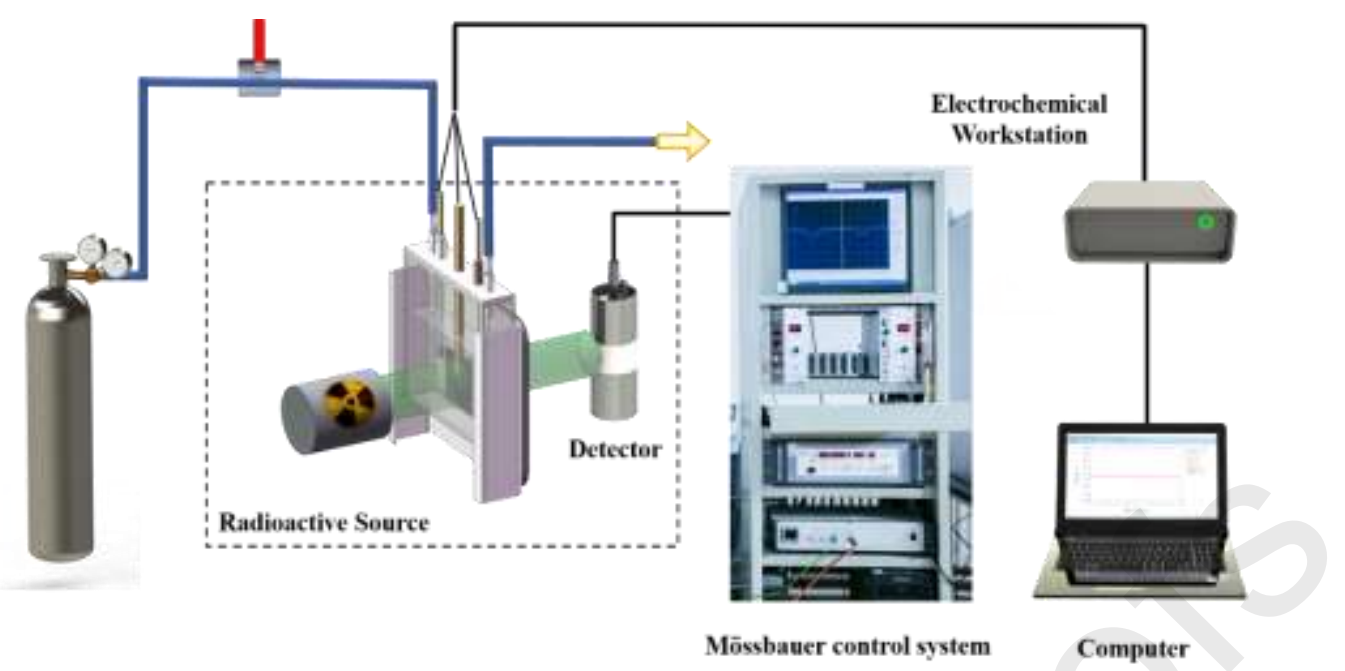

Scheme 1. The self-developed operando electrochemical ${ }^{57} \mathrm{Fe}$ Mössbauer instrument.

\section{Results and discussion}

\subsection{Structure of the catalyst}

As described above, the $\mathrm{NiFe}_{m}$ (oxy)hydroxides ( $\mathrm{NiFe}_{m}-\mathrm{O}_{x} \mathrm{H}_{y}, m$ refers to the molar ratio of $\mathrm{Fe} / \mathrm{Ni}$ ) were prepared by the topotactic transformation of $\mathrm{NiFe}_{m}-\mathrm{Fe}$ PBAs $\left(\mathrm{NiFe}_{m}[\mathrm{Fe}(\mathrm{CN})]_{(m+2 / 3)}\right)$ precursors in the $2 \mathrm{M} \mathrm{KOH}$ alkaline solution. The precursors of $\mathrm{NiFe}_{m}$-Fe PBAs were prepared by the reported coprecipitation method [18]. As displayed in Fig. 1(a), the XRD patterns show the major diffraction peaks of $\mathrm{NiFe}_{m}-\mathrm{Fe}$ PBAs, which match well with that of $\mathrm{Ni}_{3}\left[\mathrm{Fe}(\mathrm{CN})_{6}\right]_{2} \cdot 10 \mathrm{H}_{2} \mathrm{O}$ (JCPDS No. 46-0906), indicating pure phase of $\mathrm{NiFe}_{m}$-Fe PBAs were prepared with $\mathrm{Ni}^{2+}$ partially replaced by $\mathrm{Fe}^{3+}$. After separately immersing the series of $\mathrm{NiFe}_{m}-\mathrm{Fe}$ PBAs in the alkaline solution, the $\mathrm{NiFe}_{m}-\mathrm{Fe}$ PBAs were topotactically converted to $\mathrm{NiFe}_{m}-\mathrm{O}_{x} \mathrm{H}_{y}$ with low crystallinity (Fig. 1b) [22]. 
(a)
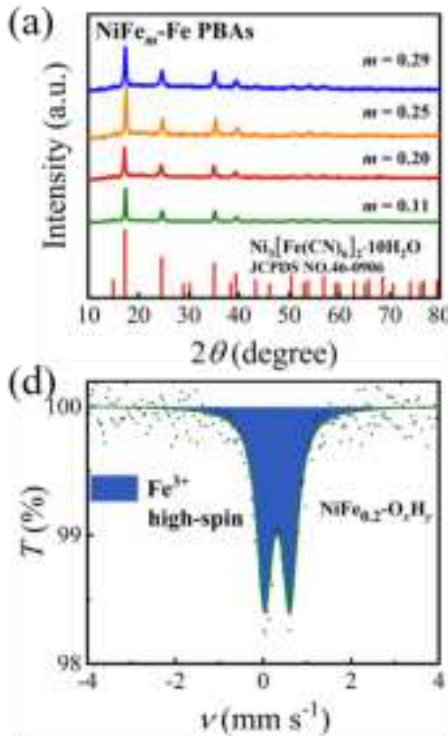

(g)

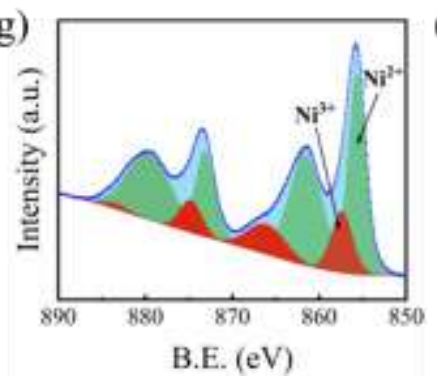

(b)

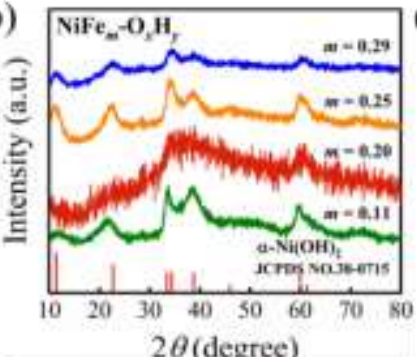

(e)

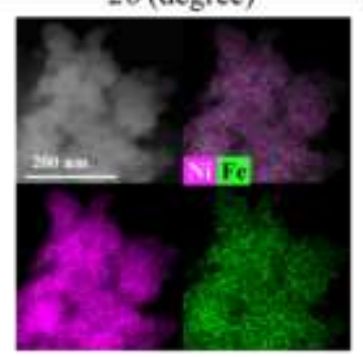

(h)

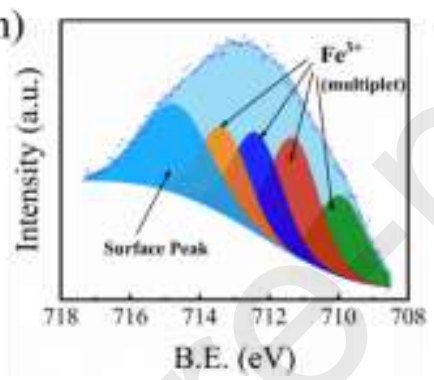

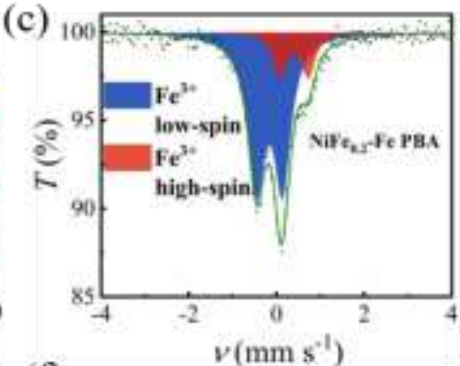

(f)

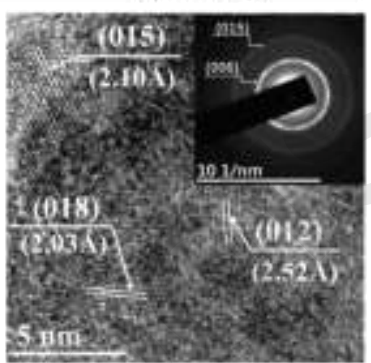

(i)

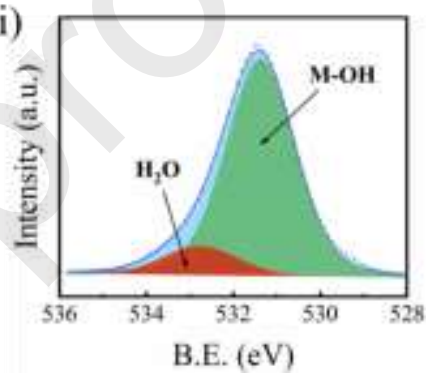

Fig. 1. XRD patterns of (a) $\mathrm{NiFe}_{m}-\mathrm{Fe}$ PBAs and (b) $\mathrm{NiFe}_{m}-\mathrm{O}_{x} \mathrm{H}_{y}$ with different molar ratios of Fe/Ni. Ex-situ ${ }^{57} \mathrm{Fe}$ Mössbauer spectra of (c) $\mathrm{NiFe}_{0.2}-\mathrm{Fe} \mathrm{PBA}$ and (d) $\mathrm{NiFe}_{0.2^{-}}$ $\mathrm{O}_{x} \mathrm{H}_{y}$. (e) TEM image, corresponding EDX elemental mappings and (f) HRTEM image of $\mathrm{NiFe}_{0.2}-\mathrm{O}_{x} \mathrm{H}_{y}$. The inset shows the SAED patterns of $\mathrm{NiFe}_{0.2}-\mathrm{O}_{x} \mathrm{H}_{y}$. XPS spectra of (g) Ni $2 p$, (h) Fe $2 p$, and (i) $\mathrm{O} 1 s$ for $\mathrm{NiFe}_{0.2}-\mathrm{O}_{x} \mathrm{H}_{y}$.

Ex-situ ${ }^{57} \mathrm{Fe}$ Mössbauer spectroscopic measurements were conducted to study the chemical states of $\mathrm{Fe}$ in the as-prepared $\mathrm{NiFe}_{m}-\mathrm{O}_{x} \mathrm{H}_{y}$ catalysts. As shown in Fig. 1(c) and Fig. S3(a-c), ex-situ ${ }^{57} \mathrm{Fe}$ Mössbauer spectra of $\mathrm{NiFe}_{m}$-Fe PBAs was observed ( $m$ $=0.11,0.20,0.25,0.29)$, which has two kinds of $\mathrm{Fe}^{3+}[23-25]$. Since $\mathrm{C}$ is stronger electron donor than $\mathrm{N}$ in the cyanogroup $\left(\mathrm{CN}^{-}\right)$, the $\mathrm{Fe}^{3+}$ in the $\left[\mathrm{Fe}(\mathrm{CN})_{6}\right]^{3+}$ large anions is low spin state while the $\mathrm{Fe}^{3+}$ that replaced the partial $\mathrm{Ni}^{2+}$ outside $\left[\mathrm{Fe}(\mathrm{CN})_{6}\right]^{3+}$ is in the high spin state [26-28], which was clearly confirmed by ex-situ Mössbauer characterization of $\mathrm{NiFe}_{m}-\mathrm{Fe}$ PBAs. In the meanwhile, with the increase of Fe doping 
amount, the proportion of high spin $\mathrm{Fe}^{3+}$ also increases gradually (Table S1), which also further indicates the successful doping of Fe with different content. After immersed in $2 \mathrm{M} \mathrm{KOH}$ aqueous solution, the shoulder absorption peaks in the Mössbauer spectra of $\mathrm{NiF}_{m}$-Fe PBAs corresponding to $\left[\mathrm{Fe}(\mathrm{CN})_{6}\right]^{3-}$ was disappeared, indicating that the $\mathrm{NiFe}_{m}-\mathrm{Fe}$ PBAs has been completely destructed and transformed into $\mathrm{NiFe}_{m}-\mathrm{O}_{x} \mathrm{H}_{y}$ (Fig. 1d and Fig. 3Sd-f)), which is well consistent with the XRD results (Fig. 1b).

Fig. 1(e) displays a TEM image and the corresponding EDX elemental mappings of the selected $\mathrm{NiFe}_{0.2}-\mathrm{O}_{x} \mathrm{H}_{y}$, which shows uniform distributions of $\mathrm{Ni}$ and $\mathrm{Fe}$. The observed interplanar spacings of 2.03, 2.10 and $2.52 \AA$ from the HRTEM image can be assigned to the (015), (018) and (012) planes of the crystal structure $\alpha-\mathrm{Ni}(\mathrm{OH})_{2}($ Fig. 1f), respectively [29], suggesting the distribution of Fe species in the lattice of $\alpha$ $\mathrm{Ni}(\mathrm{OH})_{2}$. Additionally, the crystal planes of (015) and (006) from $\alpha-\mathrm{Ni}(\mathrm{OH})_{2}$ are clearly observable in the SAED patterns (inset in Fig. 1f), which is well consistent with the results of Mössbauer spectrum (Fig. 1d) and further demonstrates that the precursor $\mathrm{NiFe}_{0.2}-\mathrm{Fe}$ PBA has been fully converted to $\mathrm{NiFe}_{0.2}-\mathrm{O}_{x} \mathrm{H}_{y}$ after being immersed in the alkaline solution.

The surface composition and valence states of $\mathrm{NiFe}_{m}-\mathrm{O}_{x} \mathrm{H}_{y}$ were analyzed by the XPS technique. Table S2 lists the binding energies of Ni $2 p, \mathrm{Fe} 2 p, \mathrm{O} 1 s$ and $\mathrm{N} 1 s$ obtained from XPS spectra of the selected $\mathrm{NiFe}_{0.2}-\mathrm{O}_{x} \mathrm{H}_{y}$ and $\mathrm{NiFe}_{0.2}-\mathrm{Fe}$ PBA. All binding energies were calibrated by a standard sample of carbon $(\mathrm{C} 1 s=248.8 \mathrm{eV})$. As shown in Fig. $1(\mathrm{~g})$, the peaks at 855.6 and $857.4 \mathrm{eV}$ of $\mathrm{Ni} 2 p$ for $\mathrm{NiFe}_{0.2}-\mathrm{O}_{x} \mathrm{H}_{y}$ can be assigned to $\mathrm{Ni}^{2+}$ and $\mathrm{Ni}^{3+}$, respectively. As shown in Fig. $\mathrm{S} 4(\mathrm{a})$, apart from $\mathrm{Ni}^{\mathrm{II}}, \mathrm{Ni}^{\mathrm{III}}$ was also observed in the Ni $2 p$ XPS spectrum of $\mathrm{NiFe}_{0.2}-\mathrm{Fe}$ PBA, which can be explained as PBAs are unstable under $\mathrm{X}$-ray irradiation and then $\mathrm{Ni}^{\mathrm{II}}$ was partially oxidized into $\mathrm{Ni}^{\mathrm{III}}$ on the surface of $\mathrm{NiFe}_{0.2}-\mathrm{Fe}$ PBA [30,31]. Compared to the $\mathrm{Fe} 2 p$ 
XPS spectrum for $\mathrm{NiFe}_{0.2}$-Fe PBA (Fig. S4b), a broad spectral band of that for $\mathrm{NiFe}_{0.2}$ $\mathrm{O}_{x} \mathrm{H}_{y}$ was observed (Fig. 1h), suggesting presence of multiple Fe species as previously reported by several groups [32,33]. The Fe $2 p$ spectrum for $\mathrm{NiFe}_{0.2}-\mathrm{Fe} \mathrm{PBA}$ (Fig. S4b) indicates the presence of low spin $\mathrm{Fe}^{\mathrm{III}}$ which is bonded to $\mathrm{C}$ of cyanogroup (Fe $\left.{ }^{\mathrm{III}}-\mathrm{CN}\right)$ and high spin $\mathrm{Fe}^{\mathrm{III}}$ bonded to $\mathrm{N}$ of cyanogroup $\left(\mathrm{Fe}^{\mathrm{III}}-\mathrm{NC}\right)$ which has a higher binding energy than $\mathrm{Fe}^{\mathrm{III}}-\mathrm{CN}$ [34]. This is consistent with the analysis of the ex-situ ${ }^{57} \mathrm{Fe}$ Mössbauer spectrum shown in Fig. 1(c). In addition, the observed $\mathrm{Fe}^{\mathrm{II}}$ in the XPS spectrum of $\mathrm{NiFe}_{0.2}$-Fe PBA (Fig. S4b) can be reasonably explained as that $\mathrm{Fe}^{\mathrm{III}}$ was partially reduced under X-ray irradiation [31].

The $\mathrm{O} 1 s$ peak of XPS spectrum of $\mathrm{NiFe}_{0.2}-\mathrm{O}_{x} \mathrm{H}_{y}$ was observed significantly shifted to lower binding energies as compared to that of $\mathrm{NiFe}_{0.2}$-Fe PBA (Fig. S5a). The main peak at $531.4 \mathrm{eV}$ can be attributed to $\mathrm{M}(\mathrm{Ni}, \mathrm{Fe})-\mathrm{OH}$ and the small peak at binding energy of $532.8 \mathrm{eV}$ can be assigned to coordinated water (Fig. 1i) [32,35]. The high intensity of the $\mathrm{M}(\mathrm{Ni}, \mathrm{Fe})-\mathrm{OH}$ peak convincingly demonstrates that $\mathrm{NiFe}_{0.2}-\mathrm{O}_{x} \mathrm{H}_{y}$ was formed after the alkali treatment, which is consistent with the results of other characterizations. As shown in Fig. S5(a), down, the main O $1 s$ peak at $532.5 \mathrm{eV}$ and the small O $1 s$ peak at $529.9 \mathrm{eV}$ for $\mathrm{NiFe}_{0.2}-\mathrm{Fe}$ PBA should be assigned to the water of crystallization and the very weak oxidation of the surface layer to $\mathrm{Ni}(\mathrm{Fe})$-oxides, respectively [31].

The peaks observed at the binding energies of the $\mathrm{N} 1 s$ XPS spectra of $\mathrm{NiFe}_{0.2-}$ $\mathrm{O}_{x} \mathrm{H}_{y}$ centered at $398.0 \mathrm{eV}$ and $\mathrm{NiFe}_{0.2}-\mathrm{Fe} \mathrm{PBA}$ centered at $398.2 \mathrm{eV}$ can be assigned to cyanogroup (Fig. S5b) [31]. The N $1 s$ peak of $\mathrm{NiFe}_{0.2}-\mathrm{O}_{x} \mathrm{H}_{y}$ is much weaker than that of $\mathrm{NiFe}_{0.2}-\mathrm{Fe} \mathrm{PBA}$, indicating there are few residual $\left[\mathrm{Fe}(\mathrm{CN})_{6}\right]^{3-}$ large anions at the surface of $\mathrm{NiFe}_{0.2}-\mathrm{O}_{x} \mathrm{H}_{y}$. This also demonstrates that the $\left[\mathrm{Fe}(\mathrm{CN})_{6}\right]^{3-}$ of $\mathrm{NiFe}_{0.2}-\mathrm{Fe}$ PBA was almost dissociated after topotactically construction by anions exchange, which then 
generated $\mathrm{NiFe}_{0.2}-\mathrm{O}_{x} \mathrm{H}_{y}$. It is in accordance with the results obtained by ${ }^{57} \mathrm{Fe}$ Mössbauer spectroscopy and XRD.

\subsection{Electrocatalytic performance for OER}

The electrocatalytic performances of $\mathrm{NiFe}_{m}-\mathrm{O}_{x} \mathrm{H}_{y}$ for OER were assessed by linear sweep voltammetry (LSV) in $1.0 \mathrm{M} \mathrm{KOH}$ aqueous solution at a scan rate of $1 \mathrm{mV} \mathrm{s}^{-1}$ with iR correction (Fig. 2a) after electrochemical activation (Fig. S6). As shown in Fig. 2(a), the OER activity could be modulated by rational changing the molar ratio of $\mathrm{Fe} / \mathrm{Ni}$ in $\mathrm{NiFe}_{m}-\mathrm{O}_{x} \mathrm{H}_{y}$. As plotted in Fig. 2(b and c), an optimized catalytic performance with a low overpotential of $263 \mathrm{mV}$ at the current density of $10 \mathrm{~mA} \mathrm{~cm}{ }^{-2}$ and a small Tafel slope of $35 \mathrm{mV} \mathrm{dec}{ }^{-1}$ was achieved over $\mathrm{NiFe}_{0.2}-\mathrm{O}_{x} \mathrm{H}_{y}$, which is superior to the state-ofthe-art $\mathrm{RuO}_{2}$ catalyst with a overpotential potential of $288 \mathrm{mV}$ at the same current density of $10 \mathrm{~mA} \mathrm{~cm}{ }^{-2}$ with a Tafel slope of $55 \mathrm{mV} \mathrm{dec}^{-1}$. In addition, the catalytic stability of $\mathrm{NiFe}_{0.2}-\mathrm{O}_{x} \mathrm{H}_{y}$ was also examined using the chronopotentiometry method. As shown in Fig. 2(d), the time-dependent potential curves were recorded at a large current density of $100 \mathrm{~mA} \mathrm{~cm}^{-2}$ on $\mathrm{Ni}$ foam (thickness, $0.34 \mathrm{~mm}$ ) with different catalyst loading amounts $\left(0.16,0.23 \mathrm{mg} \mathrm{cm}^{-2}\right)$ showing no significant activity decay of $\mathrm{NiFe}_{0.2}-\mathrm{O}_{x} \mathrm{H}_{y}$ over $100 \mathrm{~h}$ of continuous reaction and the inset shows chronopotentiometric curves of $\mathrm{NiFe}_{0.2}-\mathrm{O}_{x} \mathrm{H}_{y}$ supported on a glass carbon electrode (diameter, $5 \mathrm{~mm}$ ) at a constant current density of $10 \mathrm{~mA} \mathrm{~cm}{ }^{-2}$, which all indicate that $\mathrm{NiFe}_{0.2}-\mathrm{O}_{x} \mathrm{H}_{y}$ has a very good stability. 
(a)
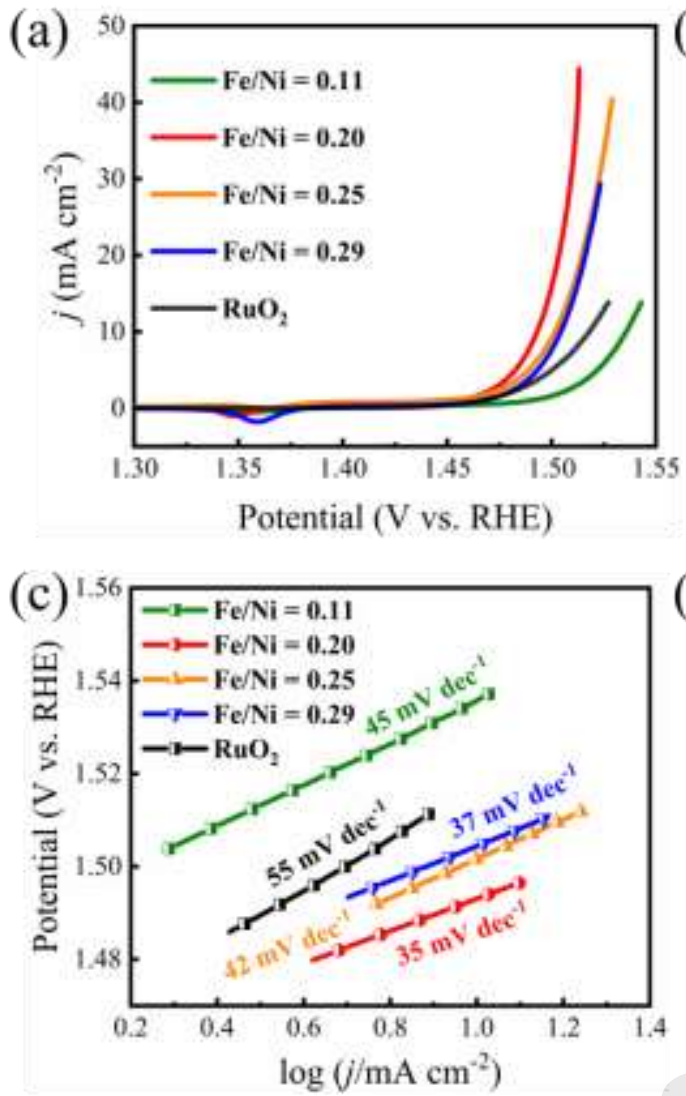

(b)

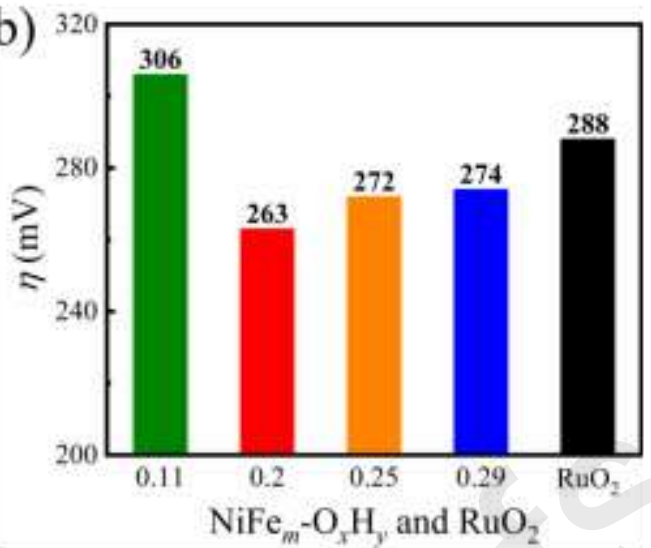

(d)

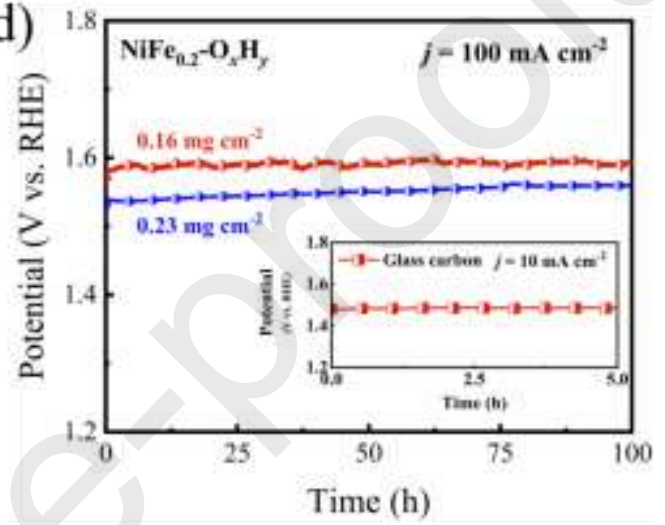

Fig. 2. (a) The OER polarization curves with iR correction. (b) Overpotentials at $10 \mathrm{~mA}$ $\mathrm{cm}^{-2}$ and (c) Tafel plots of $\mathrm{NiFe}_{m}-\mathrm{O}_{x} \mathrm{H}_{y}$ with different molar ratios of $\mathrm{Fe} / \mathrm{Ni}$ and commercial $\mathrm{RuO}_{2}$. (d) Chronopotentiometric curves of $\mathrm{NiFe}_{0.2}-\mathrm{O}_{x} \mathrm{H}_{y}$ on $\mathrm{Ni}$ foam (thickness, $0.34 \mathrm{~mm}$ ) with different catalyst loading $\left(0.16,0.23 \mathrm{mg} \mathrm{cm}^{-2}\right)$ at a constant current density of $100 \mathrm{~mA} \mathrm{~cm}^{-2}$ for $100 \mathrm{~h}$. The inset shows chronopotentiometric curves of $\mathrm{NiFe}_{0.2}-\mathrm{O}_{x} \mathrm{H}_{y}$ supported on a glass carbon electrode (diameter, $5 \mathrm{~mm}$ ) at a constant current density of $10 \mathrm{~mA} \mathrm{~cm}^{-2}$

\subsection{Operando Raman and ${ }^{57} \mathrm{Fe}$ Mössbauer spectroscopic characterizations}

To investigate the real active phase of $\mathrm{NiFe}_{m}-\mathrm{O}_{x} \mathrm{H}_{y}$ in OER, firstly, ex-situ Raman spectroscopy was performed (Fig. 3a and Fig. S7). As shown in Fig. 3(a), NiFe ${ }_{0.2}-\mathrm{O}_{x} \mathrm{H}_{y}$ has two Raman bands at 463 and $530 \mathrm{~cm}^{-1}$, with the intensity of the band at $530 \mathrm{~cm}^{-1}$ stronger than that of $463 \mathrm{~cm}^{-1}$, which is well consistent with that of the type of $\alpha$ $\mathrm{Ni}(\mathrm{OH})_{2}$ structure which has low Raman scattering cross-section [36-38]. After 
electrochemical activation, both bands of $\mathrm{NiFe}_{0.2}-\mathrm{O}_{x} \mathrm{H}_{y}$ underwent an irreversible change and the intensity of the band at $476 \mathrm{~cm}^{-1}$ was obviously stronger than that of the band at $559 \mathrm{~cm}^{-1}$. It is assigned to $\gamma-\mathrm{NiOOH}$ because of resonance Raman enhancement of $\gamma$-NiOOH [39]. Concurrently, the band intensities greatly increased, indicating a phase transformation from the phase structure of $\alpha-\mathrm{Ni}(\mathrm{OH})_{2}$ to $\gamma-\mathrm{NiOOH}[36,38]$. Meanwhile, Fig. S6 shows the electrochemical activation curves of $\mathrm{NiFe}_{0.2}-\mathrm{O}_{x} \mathrm{H}_{y}$ for 100 cycles and cyclic voltammetry curves of $\mathrm{NiFe}_{0.2}-\mathrm{O}_{x} \mathrm{H}_{y}$ before (black curves) and after the electrochemical activation (red curves), and these results also imply the phase transformation of $\mathrm{NiFe}_{0.2}-\mathrm{O}_{x} \mathrm{H}_{y}$ during electrochemical activation.
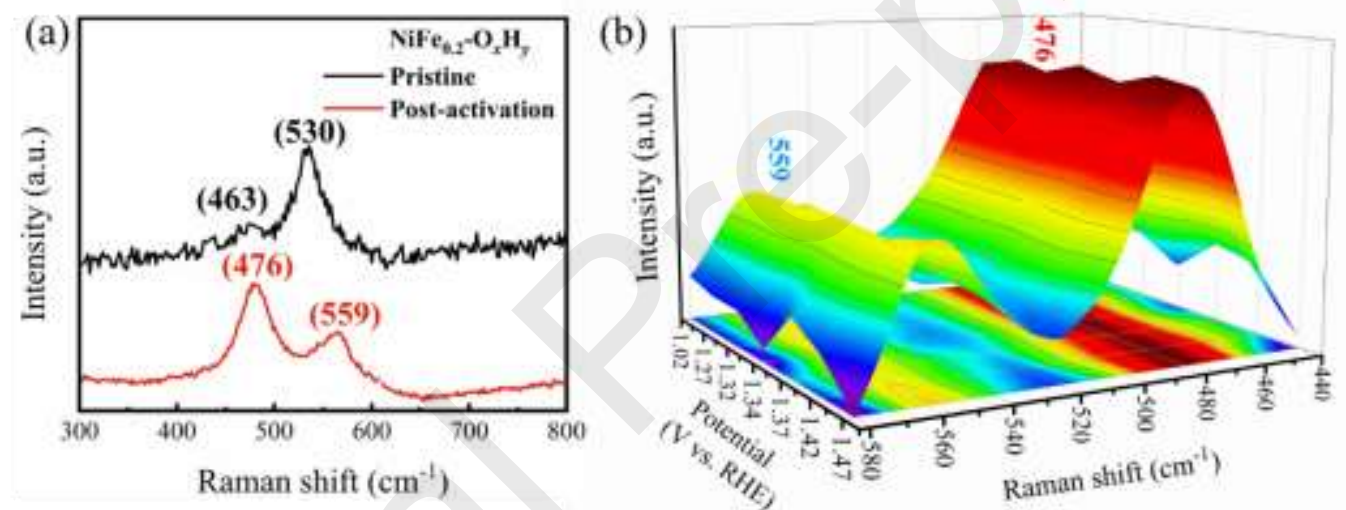

Fig. 3. (a) Raman spectra of $\mathrm{NiFe}_{0.2}-\mathrm{O}_{x} \mathrm{H}_{y}$ before (black) and after (red) applying anodic potential. (b) Operando Raman spectra of $\mathrm{NiFe}_{0.2}-\mathrm{O}_{x} \mathrm{H}_{y}$ collected at different applied potentials (V vs. RHE).

Operando Raman measurements were conducted to further study the evolution of crystal phase of $\gamma-\mathrm{NiOOH}$ in the selected $\mathrm{NiFe}_{0.2}-\mathrm{O}_{x} \mathrm{H}_{y}$ during OER. Negligible changes could be observed for the bands at 476 and $559 \mathrm{~cm}^{-1}$ when increasing the applied potentials from 1.02 to $1.47 \mathrm{mV}$ (vs. RHE) (Fig. 3b), illustrating that the crystal phase of $\gamma-\mathrm{NiOOH}$ was stable and the phase transformation was irreversible. Based on previous theoretical studies, $\mathrm{NiOOH}$ has been considered as ineffective to produce $\mathrm{O}$ 
radical [17]. However, the $\mathrm{Ni}^{3+}$ ions in Fe-doped $\gamma$-NiOOH could be increased the electron donating ability of bridging oxygen atoms, thus providing a stable environment for the in-situ production high valence state irons for the generation of active $\mathrm{O}$ intermediates $[17,20]$.

Operando ${ }^{57} \mathrm{Fe}$ Mössbauer spectroscopy measurements were carried out to further investigate the evolution of $\mathrm{Fe}$ species in the selected $\mathrm{NiFe}_{0.2}-\mathrm{O}_{x} \mathrm{H}_{y}$ during OER. Negligible change was observed in the isomer shift value of $\mathrm{NiFe}_{0.2}-\mathrm{O}_{x} \mathrm{H}_{y}$ before and after electrochemical activation (Fig. S8), indicating that the valence state $\left(\mathrm{Fe}^{3+}\right)$ and spin state (high spin) of $\mathrm{Fe}^{3+}$ in $\mathrm{NiFe}_{0.2}-\mathrm{O}_{x} \mathrm{H}_{y}$ are the same before and after the electrochemical activation. The quadrupole splitting value of $\mathrm{Fe}^{3+}$ was observed smaller than the one before activation (Table S3), indicating that a more regular geometry of $\mathrm{Fe}^{3+}$ in the $\gamma$-phase $\mathrm{NiOOH}$ structure than that of the $\alpha$-phase $\mathrm{Ni}(\mathrm{OH})_{2}$ structure.

As shown in Fig. S9(a and b), the operando ${ }^{57} \mathrm{Fe}$ Mössbauer spectra of $\mathrm{NiFe}_{0.2^{-}}$ $\mathrm{O}_{x} \mathrm{H}_{y}$ collected at $1.22 \mathrm{~V}$ and $1.32 \mathrm{~V}$ (vs. RHE) are almost the same as the one collected at the open circuit voltage (Fig. 4a), and only one doublet is observed which is attributed to high spin $\mathrm{Fe}^{3+}$. However, a small shoulder peak with a isomer shift value of -0.25 $\mathrm{mm} \mathrm{s}^{-1}$ starts to develop (Fig. 4b) at an applied potential of $1.37 \mathrm{~V}$ (vs. RHE), which is attributed to the $\mathrm{Fe}^{4+}[17,24]$. The content of $\mathrm{Fe}^{4+}$ further increases as the applied anode potential increases (Fig. 4c, d and Fig. S9c). What's more, the content of $\mathrm{Fe}^{4+}$ reaches $\sim 40 \%$ (Fig. 4e) at $1.57 \mathrm{~V}$ (vs. RHE). Then the $\mathrm{Fe}^{4+}$ completely disappears after removing the applied potential (Fig. 4f), reflecting the critical role of $\mathrm{Fe}^{4+}$ species in OER. In the meantime, there was little change in the current during operando Mössbauer spectroscopy measurements (Fig. 4g and Fig. S10), which also indicates $\mathrm{NiFe}_{0.2}-\mathrm{O}_{x} \mathrm{H}_{y}$ has a good stability in OER. In combination with the cyclic voltammetry curves (Fig. 4h), it's clear that there's already a lot of $\mathrm{Fe}^{4+}(\sim 12 \%$ in total iron ions) 
being generated at around the OER onset (Fig. 4c), and Ni/Fe magnetic moment experiments also suggest that $\mathrm{Fe}^{3+}$ is more feasible to be oxidized to a higher oxidation [40]. It is different from previous tests, in which $\mathrm{Fe}^{4+}$ was observed at a higher potential rather than around onset potential (Table S4) [17].

Moreover, the in-situ production of abundant $\mathrm{Fe}^{4+}$ near the OER onset potential, combining with the positive correlation between the $\mathrm{Fe}^{4+}$ content and electric current under different applied potential (Fig. 4i), further proved the critical role of $\mathrm{Fe}^{4+}$ species for water oxidation. The newly produced $\mathrm{Fe}^{4+}$ without observing quadrupole splitting in the operando Mössbauer spectra reflects the relatively regular octahedral geometry of iron atoms $\left(\gamma\right.$-phase $\mathrm{NiOOH}$ structure) $[41,42]$. In particular, one regular $\mathrm{FeO}_{6}$ octahedron should be surrounded by six regular $\mathrm{NiO}_{6}$ octahedrons so that the structure can create discrete $\mathrm{Fe}^{4+}$ domains within the lattice $[16,17,41,43]$. All these results are well consistent with the previous DFT studies $[16,20]$. The abundant high spin $\mathrm{Fe}^{4+}$ sites with electrophilicity could provide a more stable environment than $\mathrm{Fe}^{3+}$ for the generation of active $\mathrm{O}$ intermediates in OER [20,44,45]. 

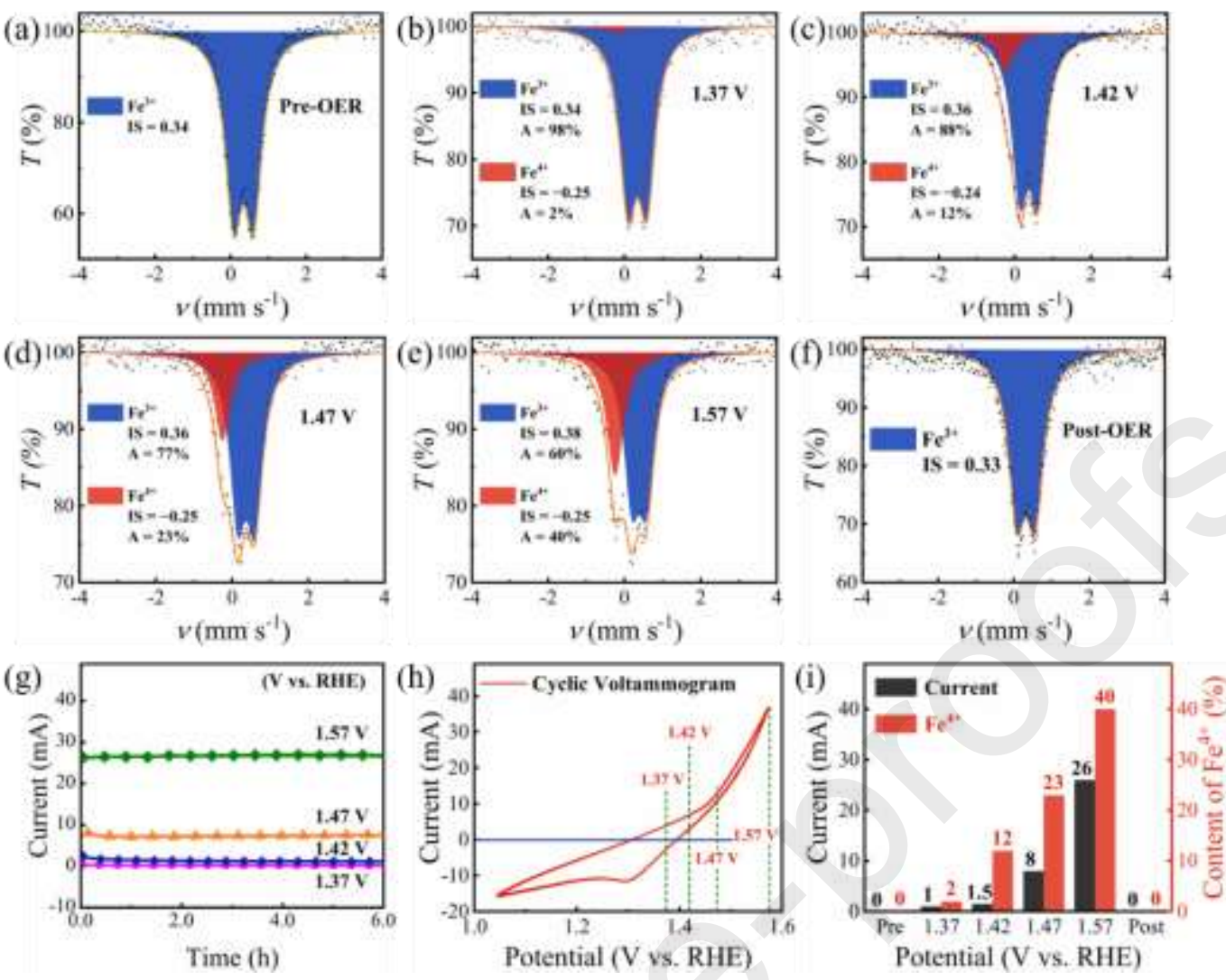

Fig. 4. Operando ${ }^{57} \mathrm{Fe}$ Mössbauer spectra of $\mathrm{NiFe}_{0.2}-\mathrm{O}_{x} \mathrm{H}_{y}$ collected at (a) the open circuit voltage, (b) $1.37 \mathrm{~V}$, (c) $1.42 \mathrm{~V}$, (d) $1.47 \mathrm{~V}$, and (e) $1.57 \mathrm{~V}$ (vs. RHE). (f) Ex-situ ${ }^{57} \mathrm{Fe}$ Mössbauer spectrum of $\mathrm{NiFe}_{0.2}-\mathrm{O}_{x} \mathrm{H}_{y}$ collected after OER. The unit of ${ }^{57} \mathrm{Fe}$ Mössbauer parameter of isomer shift (IS) is $\mathrm{mm} \mathrm{s}^{-1}$. (g) The current-time curves at different applied potentials obtained during the operando measurements. (h) The cyclic voltammogram without $\mathrm{iR}$ correction of $\mathrm{NiFe}_{0.2}-\mathrm{O}_{x} \mathrm{H}_{y}$ recorded during the operando measurements. (f) The content of $\mathrm{Fe}^{4+}$ and corresponding electric current determined at different applied potentials.

\section{Conclusions}

In conclusion, topotactic transformation was developed as a facile strategy for synthesis $\mathrm{NiFe}_{m}-\mathrm{O}_{x} \mathrm{H}_{y}$. A low overpotential of $263 \mathrm{mV}$ at the current density of $10 \mathrm{~mA}$

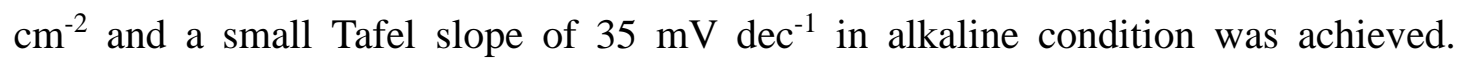
Operando Raman results confirmed that the Ni species exist mainly in the form of $\gamma$ $\mathrm{NiOOH}$ phase structure after electrochemical activation and the transformation from $\alpha$ - 
phase to $\gamma$-phase is irreversible. In addition, the in-situ produced $\mathrm{Fe}^{4+}$ with relative content as high as $\sim 40 \%$ was observed from operando Mössbauer measurement at 1.57 $\mathrm{V}$ (vs. RHE). The positive correlation between the $\mathrm{Fe}^{4+}$ content and OER current at various applied potentials implies the critical role of $i$-situ produced $\mathrm{Fe}^{4+}$ species for catalyzed water oxidation reaction.

\section{Acknowledgments}

This work was financially supported by the National Natural Science Foundation of China (21476232, 21961142006), the International Partnership Program of Chinese Academy of Sciences (121421KYSB20170020) and the State Key Laboratory of Catalysis in Dalian Institute of Chemical Physics (N-16-07). Zhichong Kuang thanks the Prof. Bin Liu in Nanyang Technological University for help in electrochemistry testing and the manuscript revision. 


\section{References}

[1] N.S. Lewis, D.G. Nocera, Proc. Natl. Acad. Sci. U. S. A. 103 (2006) 15729-15735. [2] M.G. Walter, E.L. Warren, J.R. McKone, S.W. Boettcher, Q.X. Mi, E.A. Santori, N.S. Lewis, Chem. Rev. 110 (2010) 6446-6473.

[3] W.H. Lai, L.F. Zhang, W.B. Hua, S. Indris, Z.C. Yan, Z. Hu, B.W. Zhang, Y.N. Liu, L. Wang, M. Liu, R. Liu, Y.X. Wang, J.Z. Wang, Z.P. Hu, H.K. Liu, S.L. Chou, S.X. Dou, Angew. Chem. Int. Ed. 58 (2019) 11868-11873.

[4] C. Sun, X. Guo, J. Zhang, G. Han, D. Gao, X. Gao, J. Energy Chem. 38 (2019) 3440.

[5] B.M. Hunter, H.B. Gray, A.M. Müller, Chem. Rev. 116 (2016) 14120-14136.

[6] L. Zhou, M. Shao, M. Wei, X. Duan, J. Energy Chem. 26 (2017) 1094-1106.

[7] C. Tang, H.S. Wang, H.F. Wang, Q. Zhang, G.L. Tian, J.Q. Nie, F. Wei, Adv. Mater. 27 (2015) 4516-4522.

[8] C. Tang, H.F. Wang, X.L. Zhu, B.Q. Li, Q. Zhang, Part. Part. Syst. Charact. 33 (2016) 473-486.

[9] G. Shen, R. Zhang, L. Pan, F. Hou, Y. Zhao, Z. Shen, W. Mi, C. Shi, Q. Wang, X. Zhang, J.J. Zou, Angew. Chem. Int. Ed. 59 (2020) 2313-2317.

[10] K.Y. Zhu, X.F. Zhu, W.S. Yang, Angew. Chem. Int. Ed. 58 (2019) 1252-1265.

[11] W. Zhang, D.H. Li, L.Z. Zhang, X.L. She, D.J. Yang, J. Energy Chem. 39 (2019) 39-53.

[12] X. Deng, J. Huang, H. Wan, F. Chen, Y. Lin, X. Xu, R. Ma, T. Sasaki, J. Energy Chem. 32 (2019) 93-104.

[13] Y. Qin, F. Wang, J. Shang, M. Iqbal, A. Han, X. Sun, H. Xu, J. Liu, J. Energy Chem. 43 (2020) 104-107.

[14] X. Yang, Q.Q. Chen, C. J. Wang, C.C. Hou, Y. Chen, J. Energy Chem. 35 (2019) 197-203.

[15] C. Tang, H.F. Wang, H.S. Wang, F. Wei, Q. Zhang, J. Mater. Chem. A (2016) 32103216.

[16] Z.K. Goldsmith, A.K. Harshan, J.B. Gerken, M. Voros, G. Galli, S.S. Stahl, S. Hammes-Schiffer, Proc. Natl. Acad. Sci. U. S. A. 114 (2017) 3050-3055.

[17] J.Y. Chen, L. Dang, H. Liang, W. Bi, J.B. Gerken, S. Jin, E.E. Alp, S.S. Stahl, J. Am. Chem. Soc. 137 (2015) 15090-15093.

[18] H.S. Ahn, A.J. Bard, J. Am. Chem. Soc. 138 (2016) 313-318.

[19] C. Kuai, Y. Zhang, D. Wu, D. Sokaras, L. Mu, S. Spence, D. Nordlund, F. Lin, X.W. Du, ACS Catal. 9 (2019) 6027-6032.

[20] H. Xiao, H. Shin, W.A. Goddard, 3rd, Proc. Natl. Acad. Sci. U. S. A. 115 (2018) 5872-5877.

[21] X. Li, L. Yuan, J. Wang, L. Jiang, A.I. Rykov, D.L. Nagy, C. Bogdan, M.A. Ahmed, K. Zhu, G. Sun, W. Yang, Nanoscale 8 (2016) 2333-2342.

[22] K. Zhu, H. Liu, M. Li, X. Li, J. Wang, X. Zhu, W. Yang, J. Mater. Chem. A 5 (2017) 7753-7758.

[23] A.I. Rykov, J. Wang, T. Zhang, K. Nomura, Hyperfine Interact. 218 (2012) 139143.

[24] F. Menil, J. Phys. Chem. Solids 46 (1985) 763-789. 
[25] K. Liu, A.I. Rykov, J.H. Wang, T. Zhang, Recent Advances in the Application of Mo beta bauer Spectroscopy in Heterogeneous Catalysis, in: F.C. Jentoft (Ed.) Adv. Catal., Elsevier Academic Press Inc, San Diego, 2015, pp. 1-142.

[26] J.S. Miller, J.L. Manson, Acc. Chem. Res. 34 (2001) 563-570.

[27] P. Gütlich, C. Schröder, V. Schünemann, Spectroscopy Europe 24 (2012) 21-32. [28] X.N. Li, K.Y. Zhu, J.F. Pang, M. Tian, J.Y. Liu, A.I. Rykov, M.Y. Zheng, X.D. Wang, X.F. Zhu, Y.Q. Huang, B. Liu, J. H. Wang, W.S. Yang, T. Zhang, Appl. Catal. B. 224 (2018) 518-532.

[29] Z. Li, J. Han, L. Fan, R. Guo, Colloid Polym. Sci. 294 (2016) 681-689.

[30] S.J. Gerber, E. Erasmus, Mater. Chem. Phys. 203 (2018) 73-81.

[31] A. Cano, J. Rodríguez-Hernández, L. Reguera, E. Rodríguez-Castellón, E. Reguera, Eur. J. Inorg. Chem. 2019 (2019) 1724-1732.

[32] M. Mullet, V. Khare, C. Ruby, Surf. Interface Anal. 40 (2008) 323-328.

[33] R.P. Gupta, S.K. Sen, Phys. Rev. B 12 (1975) 15-19.

[34] W.E. Buschmann, J.Ensling, P.Gutlich, J.S. Miller, Chem. Eur. J. 5 (1999) 30193028.

[35] A. Lisowska-Oleksiak, A.P. Nowak, M. Wilamowska, M. Sikora, W. Szczerba, C. Kapusta, Synth. Met. 160 (2010) 1234-1240.

[36] D.K. Bediako, Y. Surendranath, D.G. Nocera, J. Am. Chem. Soc. 135 (2013) 36623674.

[37] M.W. Louie, A.T. Bell, J. Am. Chem. Soc. 135 (2013) 12329-12337.

[38] K.S. Joya, X. Sala, Phys. Chem. Chem. Phys. 17 (2015) 21094-21103.

[39] B.S. Yeo, A.T. Bell, J. Phys. Chem. C 116 (2012) 8394-8400.

[40] F. Dionigi, Z. Zeng, I. Sinev, T. Merzdorf, S. Deshpande, M.B. Lopez, S. Kunze, I. Zegkinoglou, H. Sarodnik, D. Fan, A. Bergmann, J. Drnec, J.F. Araujo, M. Gliech, D. Teschner, J. Zhu, W.X. Li, J. Greeley, B.R. Cuenya, P. Strasser, Nat. Commun. 11 (2020) 2522-2532.

[41] P. Axmann, O. Glemser, J. Alloys Comp. 246 (1997) 232-241.

[42] L. Trotochaud, S.L. Young, J.K. Ranney, S.W. Boettcher, J. Am. Chem. Soc. 136 (2014) 6744-6753

[43] D. Friebel, M.W. Louie, M. Bajdich, K.E. Sanwald, Y. Cai, A.M. Wise, M.J. Cheng, D. Sokaras, T.C. Weng, R. Alonso-Mori, R.C. Davis, J.R. Bargar, J.K. Norskov, A. Nilsson, A.T. Bell, J. Am. Chem. Soc. 137 (2015) 1305-1313.

[44] B.M. Hunter, J.R. Winkler, H.B. Gray, Molecules 23 (2018) 903-910.

[45] H.B. Tao, Y. Xu, X. Huang, J. Chen, L. Pei, J. Zhang, J.G. Chen, B. Liu, Joule 3 (2019) 1498-1509. 


\section{Graphical Abstract}

Exploring the relationship between high-valent iron content and current intensity of $\mathrm{NiFe}_{0.2}-\mathrm{O}_{x} \mathrm{H}_{y}$ during oxygen evolution reaction by operando ${ }^{57} \mathrm{Fe}$ Mössbauer spectroscopy.

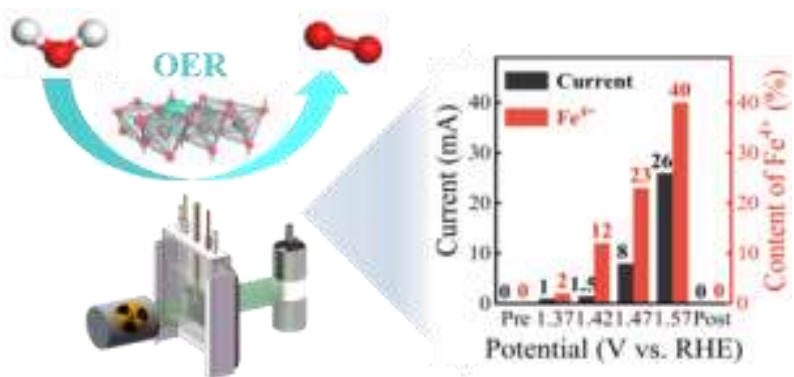

